\title{
ANALISIS SENTIMEN PUBLIK PADA MEDIA SOSIAL TWITTER TERHADAP PELAKSANAAN PILKADA SERENTAK MENGGUNAKAN ALGORITMA SUPPORT VECTOR MACHINE
}

\section{PUBLIC SENTIMENT ANALYSIS ON TWITTER SOCIAL MEDIA TO PILKADA SERENTAK EVENT USING SUPPORT VECTOR MACHINE ALGORITHM}

\author{
Atika Rahmawati ${ }^{1}$ \\ Aris Marjuni ${ }^{2}$ \\ Junta Zeniarja ${ }^{3}$ \\ JurusanTeknik Informatika, Universitas Dian Nuswantoro Semarang ${ }^{1,2,3}$ \\ e-mail: 111201207272@mhs.dinus.ac.id ${ }^{1}$, aris.marjuni@dsn.dinus.ac.id ${ }^{2}$, \\ junta@dsn.dinus.ac.id ${ }^{3}$
}

Diterima: 6 Juni 2017/ Disetujui : 13 Juni 2017

\begin{abstract}
Pilkada Serentak is a very important event for the future viability regions and countries. Through this election people can cast their vote and elect representatives of the people according to their choice. Public respond can be expressed through twitter social media. Using twitter social media sentiment analysis can then be made about the public response to the implementation of the election simultaneously. The classification process can be detected via text tweeted by twitter users. In this study, the classification of responses detected by text because it is easily obtained and applied. This study determined the classification of the response to the Indonesian language text and increase accuracy by using SVM.Tweet classification method used by the categorical approach is divided into two classes tweet basic level: positive and negative. Data collected from Indonesian twitter tweet as much as 3000. The labeling is not done manually but using clustering method that divides the 3000 data into two groups. Cluster 1 as a group of positive tweets and Cluster 2 as a negative group tweet.2700 for training data and 300 for the test data. The stage of pre-processing the data includetokenization, casenormalization, stop word detection, and stemming. The process of classification using Support Vector Machine (SVM). Accuracy of SVM showed the highest yield that is $91 \%$ compared to the $k$-means clustering with the results of $82 \%$.
\end{abstract}

Kata kunci : Pilkada serentak, sentiment analysis, twitter, $k$-means, SVM

\begin{abstract}
ABSTRAK
Pilkada serentak merupakan kegiatan yang sangat penting untuk kelangsungan masa depan daerah dan negara. Melalui pilkada ini masyarakat dapat memberikan suaranya dan memilih wakil rakyat sesuai hati nurani mereka.Respon yang diberikan masyarakat dapat diungkapkan melalui media social twitter.Melalui media sosial twitter maka dapat dibuat analisis sentimen tentang respon masyarakat terhadap pelaksanaan pilkada serentak. Proses klasifikasi dapat dideteksi melalui teks yang ditweet oleh pengguna twitter. Dalam penelitian ini, klasifikasi respon dideteksi melalui teks karena lebih mudah didapat dan diterapkan. Penelitian ini melakukan klasifikasi respon untuk teks bahasa Indonesia dan meningkatkan akurasi dengan menggunakan metode klasifikasi svm.Tweet yang digunakan berdasarkan pendekatan kategorik yang dibagi menjadi 2 kelas tweet tingkat dasar yaitu positif dan negatif. Data dikumpulkan dari twitter dengan tweet bahasa Indonesia sebanyak 3000. Pemberian label tidak dilakukan
\end{abstract}


secara manual tetapi menggunakan metode clustering yang membagi 3000 data kedalam dua kelompok. Cluster 1 sebagai kelompok tweet positif dan Cluster 2 sebagai kelompok tweet negatif. 2700 untuk data pelatihan dan 300 untuk data pengujian. Tahap pre-processing pada data meliputi tokenisasi, casenormalization, deteksi stop word, dan stemming. Proses klasifikasi menggunakan metode Support Vector Machine (SVM). Akurasi SVM menunjukkan hasil tertinggi yaitu 91\% dibanding clustering k-means dengan hasil 82\%.

Kata kunci : Pilkada serentak, analisis sentimen, twitter, k-means, SVM

\section{PENDAHULUAN}

Pilkada serentak adalah pemilihan kepala daerah yaitu gubernur, bupati, dan walikota yang dilaksanakan secara bersamaan. Komisioner Komisi Pemilihan Umum (KPU) RI, Arief Budiman, dalam Acara Rapat Koordinasi (Rakor) Persiapan dan Pengelolaan Anggaran Pemilihan Serentak Tahun 2015 menjelaskan bahwa tujuan dilaksanakannya pemilihan kepala daerah serentak supaya tercipta efektivitas dan efisiensi anggaran analisis dan opini pilkada. Selain itu keuntungan dari pilkada serentak diantaranya perencanaan pembangunan lebih sinergi antara pusat dan daerah.Keuntungan bagi rakyat yaitu tidak perlu berulang kali datang ke bilik suara.Walupun tujuan dari pilkada serentak sudah dijelas, namun masih memunculkan pro dan kontra.Hal yang menyebabkan pro dan kontra adalah perpu pilkada Nomor 1 Tahun 2014 yang bertele-tele.

Dari pembahasan masalah yang muncul diatas, maka penting untuk memahami apa yang orang pikirkan atau pendapat mereka adalah fundamental untuk pengambilan keputusan, terutama saat di mana orang mengekspresikan komentar mereka secara sukarela, yang bertujuan untuk saling bekerja sama. Opini yang disampaikan masyarakat melalui media sosial twitter akan menjadi sumber data bagi penelitian ini. Pengguna twitter tweet tentang topik apapun dalam 140 karakter membatasi dan mengikuti orang lain untuk menerima tweets mereka. Tidak seperti layanan jaringan sosial lainnya yang mengharuskan pengguna untuk memberikan teman link ke pengguna lain berteman dengan mereka, twitter mempekerjakan model jaringan sosial yang disebut "following", dimana masing masing pengguna diperbolehkan untuk memilih siapa yang dia inginkan untuk mengikuti tanpa meminta izin apapun.

Analisis sentimen baru-baru ini menjadi fokus dari banyak peneliti, karena analisis online adalah menguntungkan dan menuntut untuk riset pasar, survei ilmiah dari perspektif psikologis dan sosiologis, jajak pendapat politik, intelijen bisnis, peningkatan secara online infrastruktur belanja, dan lain-lain. SA adalah proses penggalian polaritas rakyat pendapat subjektif dari teks bahasa alami biasa._. Ada dua metode dasar yang ada, yang pertama adalah tingkat dokumen dan yang kedua adalah tingkat kalimat.Dalam tingkat dokumen, analisis didasarkan pada lengkap dokumen, sedangkan di tingkat kalimat, analisis adalah dilakukan pada tingkat kalimat.

Penelitian mengenai analisis sentiment telah banyak dilakukan. Penelitian sebelumnya yaitu dengan judul Perbandingan Teknik SVM Vs Naif-Bayes untuk Analisis sentimen Tweet:Studi Kasus dengan Piala Konfederasi FIFA 2013. Hasil Naif-Bayes dan SVM subjektivitas pengklasifikasi menunjukkan akurasi 82\% dan 84\%; dan F-ukuran 0,819 dan 0,821, berturut-turut. Hasil yang diperoleh oleh SVM sentimen classifier menunjukkan sebuah F-Measure of 0,873 dan akurasi $80,0 \%$ untuk mendeteksi sentimen polaritas. Naif-Bayes classifier sentimen disajikan F-ukuran dari 0,791 dan akurasi 72,7\%. Penggunaan classifier SVM meningkatkan akurasi dalam 8\%, ini adalah hasil yang baik.

Berdasarkan penjabaran diatas maka dilakukan penelitian tentang analisa sentiment publik terhadap pelaksanaan pilkada serentak dengan metode klasifikasi menggunakan algoritma support vectore machine (svm). Penelitian ini diharapkan dapat berguna bagi KPU 
untuk mengetahui bagaimana respon masyarakat terhadap pelaksanaan pilkada serentak.Bagi masyarakat dapat terlibat langsung dengan memberikan pendapat mengenai pelaksanaan pilkada serentak.

Penelitian menganalisis sentiment menggunakan algoritma SVM bukan yang pertama kali dilakukan. Beberapa penelitian yang relevan dengan membandingkan algoritma svm dengan algoritma lain telah dilakukan oleh peneliti sebelumnya diantaranya adalah sebagai berikut:

Peneliti terdahulu telah melakukan perbandingan algoritma svm dengan naïve bayes untuk analisis sentimen di twitter dengan studi kasus Piala Konfederasi FIFA 2013. Hasil yang dicapai dengan pengklasifikasi dikembangkan, hasil terbaik diperoleh oleh classifier yang mengimplementasikan teknik SVM. Hasil Naif-Bayes dan SVM subjektivitas pengklasifikasi menunjukkan akurasi 82\%dan 84\%; dan F-meausre masing-masing 0,819 dan 0,821.

Penelitian lain yang membandingkan dua algoritma juga telah dilakukan, mengenai analisis sentimen terhadap wacana politik pada media masa online menggunakan algoritma svm dan naïve bayes7]. Penelitian ini menjelaskan hasil analisa dengan uji data sebanyak 700 data dengan menerapkan algoritma svm menghasilkan jumlah akurasi yang lebih besar yaitu 90,50\%. Sedangkan penerapan algoritma naïve bayes dengan uji data yang sama yaitu 700 data menunjukkan akurasi hanya sebesar 59,98\%. Hasil ini dapat menyimpulkan bahwa svm memiliki tingkat akurasi yang lebih baik dari naïve bayes.

Penelitian selanjutnya yang melakukan analasis sentimen yang menggunakan lebih banyak perbandingan algoritma adalah studi banding dari seleksi fitur dan teknik pembelajaran mesin untuk analisis sentimen. Hasil penelitian menunjukkan bahwa Rasio Gain melakukan yang terbaik antara metode seleksi fitur sentimen dan SVM menunjukkan kinerja terbaik untuk klasifikasi sentimen tugas, sementara Naïve Bayes classifier memberikan hasil yang lebih baik bila digunakan dengan fitur yang lebih sedikit. Masing-masing penelitian memiliki kelemahan tidak terkecuali penelitian tentang menganalisis sentimen pengguna jejaring social menggunakan svm. Pada penelitian ini menghasilkan tingkat akurasi sebesar 81\%. Akurasi sistem salah satunya dipengaruhi oleh jumlah Data Latih yang digunakan dalam proses pelatihan.menjelaskan bahwa svm memiliki kelemahan apabila tweet memiliki makna ganda atau ambigu.

Penelitian yang paling mendekati dengan kasus yang sedang peneliti lakukan sekarang ini adalah penelitian mengenai analisis sentimen melalui media twitter menggunakan svm dengan studi kasus kpk versus kapolri. Penelitian ini menggunakan opini public melalui tweet yang dikirim melalui akun twitter tentang kpk dan kapolri yang keduanya sama-sama memiliki daya tarik untuk dibicarakan. Hasil penelitian ini menunjukkan bahwa lebih banyak jumlah sentimen negatif dari pada positif untuk keduanya.Diantara keduanya, kpk menjadi yang paling banyak dibicarakan di media sosial twitter.

\section{METODOLOGI PENELITIAN}

\subsection{Dataset}

Pengumpulan data dalam penelitian ini berasal dari data twitter dengan mendaftarkan akun untuk dapat mengakses API twitter. Setelah mendaftarkan akun maka peneliti akan mendapatkan consumer key, consumer secret, acces token, dan acces token secret. Hal ini nantinya akan digunakan untuk memanggil library twitter sehingga peneliti bisa mendapatkan data sesuai kata kunci yang dimasukkan yaitu pilkada serentak. Pemanggilan library twitter menggunakan bahasa pemrograman R. Dalam hal ini peneliti melakukan satu kali crawling data dengan mendapatkan hasil 3000 data. 
Tabel 1. Contoh Data tweet mentah

\begin{tabular}{|c|c|c|c|c|}
\hline text & created & id & $\begin{array}{l}\text { Status } \\
\text { Source }\end{array}$ & $\begin{array}{l}\text { Screen } \\
\text { Name }\end{array}$ \\
\hline $\begin{array}{l}\text { Karangasem } \\
\text { Jadi "Zona } \\
\text { Merah" } \\
\text { Pilkada } \\
\text { Serentak - } \\
\text { https://t.co/s } \\
\text { VZNoBlU6A }\end{array}$ & $\begin{array}{l}16 / 12 / 2015 \\
5: 41\end{array}$ & $\begin{array}{l}677000492 \\
988424000\end{array}$ & $\begin{array}{l}<\mathrm{a} \\
\text { href="http:// } \\
\text { www.google. } \\
\text { com/" } \\
\text { rel="nofollow } \\
\text { ">Google</a } \\
>\end{array}$ & Balitoday \\
\hline $\begin{array}{l}\text { Aher } \\
\text { Berharap } \\
\text { Pemenang } \\
\text { Pilkada } \\
\text { Serentak } \\
\text { Bisa Segera } \\
\text { Dilantik | } \\
\text { Bandung } \\
\text { https://t.co/X } \\
\text { FodkklSFM }\end{array}$ & $\begin{array}{l}16 / 12 / 2015 \\
5: 30\end{array}$ & $\begin{array}{l}676997885 \\
460930000\end{array}$ & $\begin{array}{l}<\mathrm{a} \\
\text { href="http:// } \\
\text { www.hootsuit } \\
\text { e.com" } \\
\text { rel="nofollow } \\
\text { ">Hootsuite< } \\
\text { /a }>\end{array}$ & sapa_jabar \\
\hline
\end{tabular}

\subsection{Pre-Processing}

Didalam pre-processing terdapat subproses yaitu case normalization, deteksi stop word, tokenisasi, part-of-speech (pos) tagging, parsing, stemming, dan lemmatization. Dalam penelitian ini,hanya menerapkan beberapa pre-processing keterangan sebagai berikut:

- Tokenisasi adalah proses untuk memotong teks ke karakter/ symbol, kata, frasa.

- Case normalization adalah merubah kalimat menjadi huruf kecilsemua.

- Deteksi stopword adalah proses untuk memfilter kata yang sering digunakan seperti mereka,kenapa, jika, seperti,untuk, ke,dan.

- Stemming adalah proses mengurangi kata-kata untuk bentuk katadasar.Contohnya memakan, dimakan menjadi makan.

Tabel 2 merupakan contoh pre-processing yang digunakan dalam penelitian ini. Hasil dari preprocessing akan disebut atribut.

Tabel 2.contoh pre-prosessing

\begin{tabular}{|l|l|}
\hline Tweet Mentah & Pre-pocessing \\
\hline "Karangasem Jadi "'Zona & karangasem jadi zona \\
Merah"" Pilkada Serentak - & merah pilkada serentak \\
https://t.co/sVZNoBlU6A & \\
https://t.co/SdOZuHe4ax & \\
\#karangasem \#bali" & \\
\hline $\begin{array}{l}\text { Pilkada Serentak } \\
\text { Karangasem - ANTARA }\end{array}$ & pilkada serentak \\
\hline
\end{tabular}




\begin{tabular}{|c|c|}
\hline $\begin{array}{l}\text { https://t.co/4Tzcyo4hND } \\
\text { \#karangasem \#bali }\end{array}$ & \\
\hline $\begin{array}{l}\text { Pilkada Serentak } \\
\text { Karangasem - ANTARA } \\
\text { https://t.co/4Tzcyo4hND } \\
\text { \#karangasem \#bali }\end{array}$ & $\begin{array}{l}\text { pangdam udayana } \\
\text { apresiasi pilkada } \\
\text { serentak bali langsung } \\
\text { aman }\end{array}$ \\
\hline $\begin{array}{l}\text { Pangdam Udayana Apresiasi } \\
\text { Pilkada Serentak di Bali } \\
\text { Berlangsung aman } \\
\text { https://t.co/1jrRb03tSw } \\
\text { \#karangasem \#bali }\end{array}$ & $\begin{array}{l}\text { pilkada serentak ntb } \\
\text { kondusif tingkat } \\
\text { partisipasi jadi catat } \\
\text { mataram global fm } \\
\text { lombok situasi aman }\end{array}$ \\
\hline
\end{tabular}

\subsection{Machine-Learning}

Terdapat 2 teknik machine learning,yaitu pembelajaran terbimbing (supervised learning) dan pembelajaran tidak terbimbing (unsupervised learning). Pembeda antara 2 teknik ini adalah ada atau tidaknya label pada data training. Supervised learning terdapat label tiap data yang akan digunakan pada penelitian ini, sedangkan unsupervised learning tidak.Label kelas yang digunakan tiap data meliputi 2 kategori yaitu positif dan negatif.

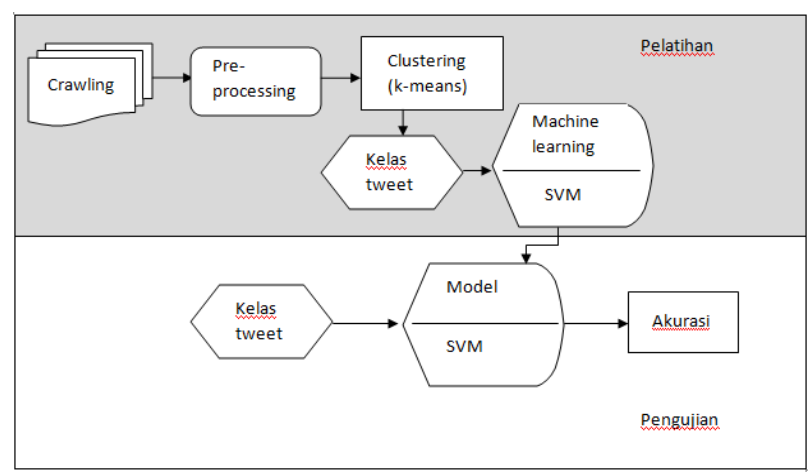

Gambar 1. Proses utama klasifikasi tweet

Pada penelitian ini menggunakan metode clustering yaitu k-means untuk pelabelan dan metode klasifikasi yaitu SVM untuk mendapatkan akurasi tertinggi.

\subsection{K-means}

Data tweet mentah yang telah melewati tahap preprocessing selanjutnya diberi label dengan menggunakan k-means. Langkah-langkah menghitung k-means :

1.

2.

centroid dengan rumus
Tentukan centroid awal

Menghitung jarak terdekat dari data ke titik

$$
d\left(x_{i}, x_{i}\right)=\sqrt{\left(x_{i} 1-x_{i} 1\right)^{2}+\left(x_{i} 2-x_{i} 2\right)^{2}}
$$

3.

Pembaruan titik centroid menggunakan rumus:

$\mu k=\frac{1}{N_{K}} \Sigma_{\mathrm{K}}^{N_{K}} x_{q}$ 


\section{$2.5 S V M$}

SVM adalah metode machinelearning yang bekerja atas prinsip Structural Risk Minimization (SRM) dengan tujuan menemukan hyperplane terbaik yang memisahkan dua buah class pada input space [ HYPERLINK "file:///H:\tugas\%2021\%20junil/Coris\ljurnal\%20atika.docx" \l "Bas13" 11 ]. Secara sederhana, SVM berusaha nmencari hyperplane terbaik untuk pemisah dua buah kelas. Metode SVM pada software Weka menggunakan Squential Minimal Optimization(SMO)12]\}. SMO adalah sebuah algoritma optimasi yang digunakan untuk melatih SVM pada kumpulan data, sehingga terciptalah model dengan pembobotan. Proses SVM pada software Weka.Software yang dikembangkan pertama kali di Selandia Baru oleh Universitas Waikato.Weka merupakan software data mining yang berbasis Java [ HYPERLINK "file:///H:\tugas\%2021\%20junil\Coris\ljurnal\%20atika.docx" \l "Wit02" 13 ]. Perhitungan manual svm menggunakan langkah - langkah berikut :

1. Tentukan vector di $\Re^{2}$. Definisi setiap titik $x=\left(x_{1}, x_{2}\right), x \neq 0$

2. Definisi arah vector $u\left(\boldsymbol{u}_{1}, \boldsymbol{u}_{2}\right)$ adalah vektor

$$
w\left(\frac{w_{12}}{\|w\|}, \frac{w_{z}}{\|w\|}\right)
$$

3. Menghitung dot produk dengan rumus $x y=x_{1} y_{1}+x_{2} y_{2}=\sum_{i=1}^{2}\left(x_{t} y_{t}\right)$

4. Mencari hyperplane dengan rumus $\mathscr{W}=\sum_{i} \kappa_{i} \xi_{i}$ selanjutnya dihitung dengan rumus iyperpiane $=w^{\mathrm{T}} x+b=0$

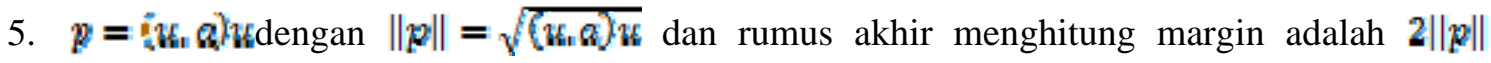

\subsection{Evaluasi}

Confusion Matrix digunakan untuk mengetahui efektifitas pemodelan klasifikasi, terdiri dari baris dan kolom yang membentuk sebuah tabel berisi label daridata uji yang diprediksi.

Confusion matrix yang terdiri dari truepositives(TP), dan truenegatives(TN) adalah klasifikasi yang benar. False positives(FP) merupakan suatu kesalahan dimanadatayang aslinya berlabel no namun dideteksi label yes,dan false negatives (FN) merupakan suatu kesalahan dimana data yang aslinya berlabel yes namun dideteksi label no. Perhitungan evaluasi dengan menggunakan tabel confusion matrix adalah sebagai berikut:

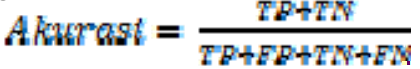

$$
\begin{aligned}
& \text { Prgetsston }=\frac{T D}{Y F+E F} \\
& \text { Recall }=\frac{T E}{T P+F N}
\end{aligned}
$$

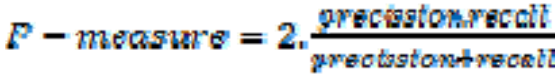

Akurasi dihitung secara global, sedangkan presisi, recall, dan f-measure dihitung per kelas tweet.Dengan demikian nilai TP, TN, FP, FN berubah tiap kelas tweet.

\section{HASIL DAN PEMBAHASAN}

Proses clustering k-means yang dilakukan menggunakan program java menghasilkan pengelompokan sebagai berikut :

Tabel 3. Hasil Pengelompokkan Data K-means

\begin{tabular}{|l|r|}
\hline \multicolumn{1}{|c|}{ Kelas } & \multicolumn{2}{|c|}{ Hasil } \\
\hline C1 (Positif) & 2482 \\
\hline C2 (Negatif) & 518 \\
\hline
\end{tabular}




\begin{tabular}{|l|r|}
\hline Jumlah & $\mathbf{3 0 0 0}$ \\
\hline
\end{tabular}

Karena metode clustering menggunakan k-means digunakan sebagai dasar pelabelan untuk klasifikasi menggunakan svm maka harus diuji dengan melakukan evaluasi.

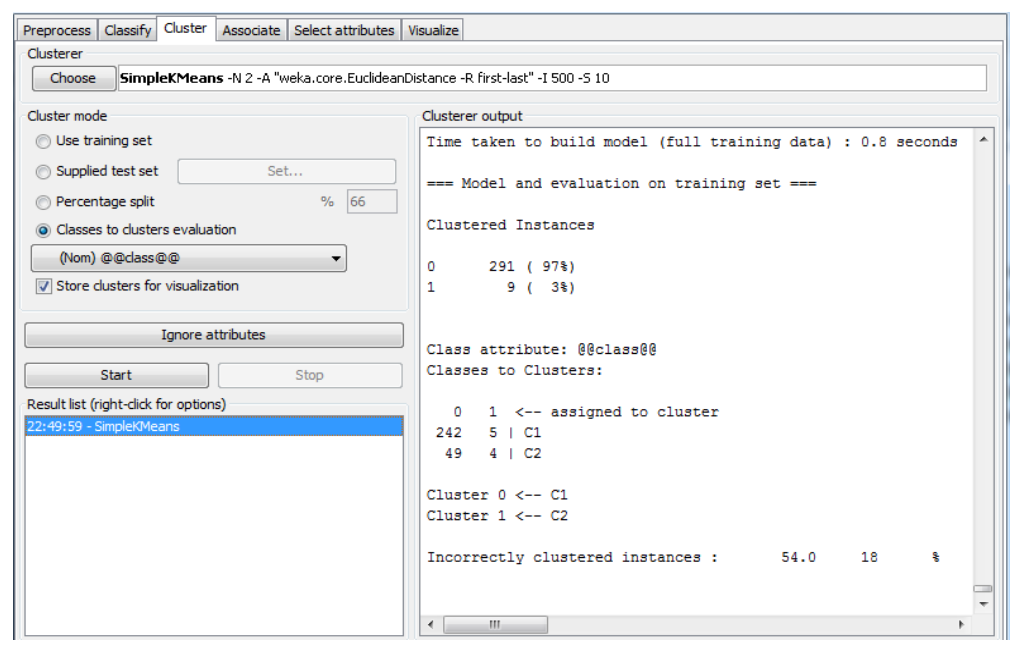

Gambar 2. Hasil Pengujian K-means

Gambar 4.1 menunjukkan bahwa persentase kesalahan saat melakukan clustering menggunakan k-means untuk pelabelan adalah 18\% dari 100\%.Jadi tingkat keakuratan data yang dilabeli adalah $82 \%$.

Proses SVM menghasilkan akurasi global sebesar 98\% yang didapat dari confusion matrix pada tabel 4.2 untuk hasil presisi, recall,dan f-measure tiap kelas tweet dapat dilihat pada tabel 4.3

Tabel 4. Confussion Matrix SVM

\begin{tabular}{|c|c|c|}
\hline A & B & Label \\
\hline 246 & 1 & A = C1(positif) \\
\hline 5 & $\mathbf{4 8}$ & B = C2(negatif) \\
\hline
\end{tabular}

Tabel 5. Hasil presisi, recall, f-measure pada SVM

\begin{tabular}{|c|c|c|c|}
\hline $\begin{array}{c}\text { Kelas } \\
\text { tweet }\end{array}$ & $\begin{array}{c}\text { Presisi } \\
(\%)\end{array}$ & Recall (\%) & $\begin{array}{c}\text { F-Measure } \\
(\%)\end{array}$ \\
\hline & & & \\
\hline Positif & 98 & 99.6 & 98.8 \\
\hline & & & \\
\hline Negatif & 98 & 90.6 & 94.1 \\
\hline
\end{tabular}

Pada gambar 3, 4, dan 5 tergambarkan grafik presisi, recall, dan f-measure pada tiap kelas dengan SVM.Adanya grafik agar kita dapat lebih mudah mengetahui perbedaan presentase tiap kelas. 


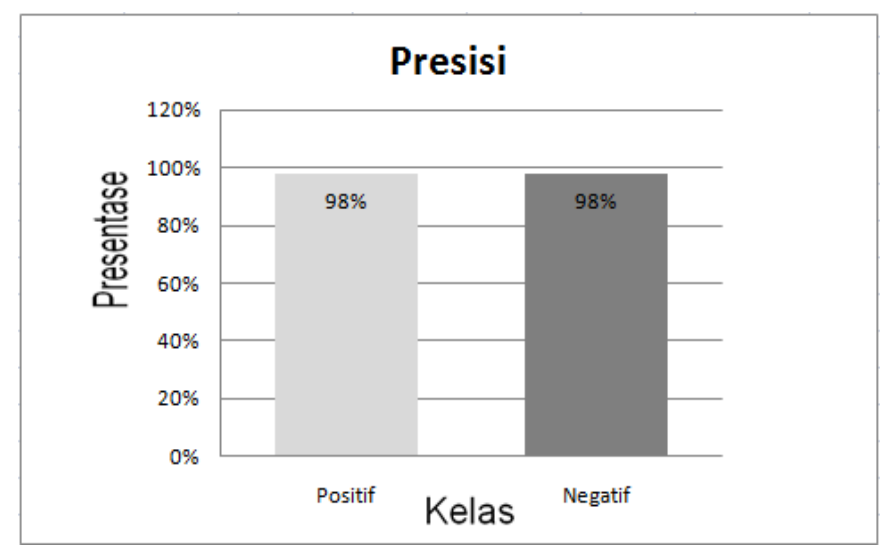

Gambar 3. Grafik Presisi SVM

Hasil presisi uji data antara kelas positif dan negative sama sama tinggi yaitu 98\%. Ini terjadi karena semua data uji berlabel positif dan negatif terdeteksi hampir tepat mendekati $100 \%$.

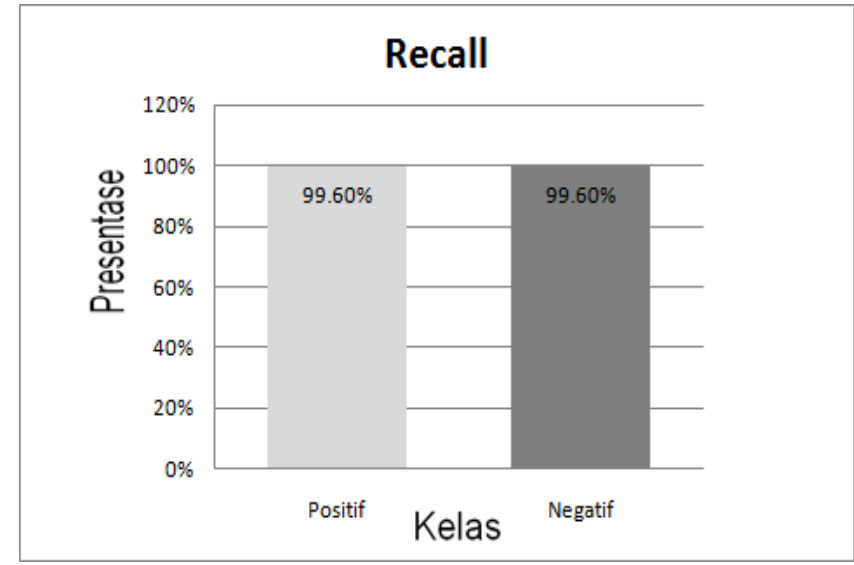

Gambar 0. Grafik Recall SVM

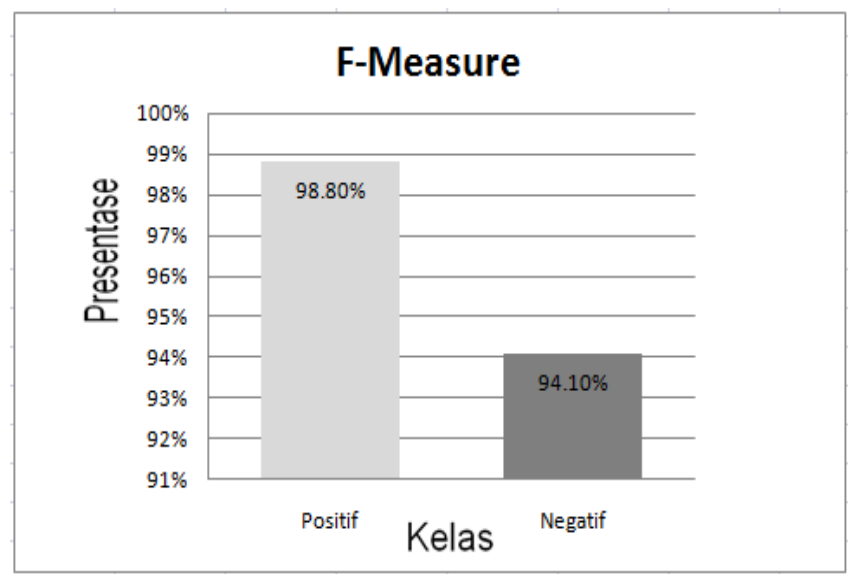

Gambar 5. Grafik F-measure SVM

Sama halnya dengan presisi, recall dan f-measure kelas positif lebih tinggi dari pada kelas negatif.Hal ini bisa terjadi karena jumlah data pada kelas negatiflebih sedikit dibanding kelas positif. 


\section{KESIMPULAN}

Berdasarkan penelitian yang dilakukan, data berasal dari twitter dengan kata kunci pilkada serentak berjumlah 3000 data.2700 data pelatihan dan 300 data pengujian. Proses diawali dengan pre-processing yang terdiri dari tokenisasi, casenormalization, deteksi stop word, dan stemming. Proses selanjutnya dilakukan proses pemberian label dengan metode clustering yaitu membagi data kedalam dua kelompok. Cluster 1 sebagai kelompok data berlabel positif dan Cluster 2 sebagai kelompok data berlabel negatif. Klasifikasi dilakukan dengan metode SVM menggunakan weka.

Penulis menyimpulkan bahwa klasifikasi tweet tentang pilkada serentak bahasa Indonesia memilki tingkat akurasi yang tinggi dengan hasil $98 \%$ dari pengujian label menggunakan metode clutering dengan algoritma k-means yaitu $82 \%$.

\section{SARAN}

Data yang digunakan dalam penelitian ini diambil dengan proses crawling satu kali saja. Peneliti selanjutnya diharapkan bisa mengambil data secara realtime. Penelitian selanjutnya juga kedepannya dapat menggunakan metode lain untuk pelabelan data agar tidak melakukan pelabelan secara manual.Proses preprocessing dalam penelitian ini masih belum sempurna dalam penyaringan kata. Peneliti lain bisa meningkatkan hasil preprocessing karena proses ini sangat menentukan hasil proses klasifikasi. Penelitian ini hanya menggunakan dua kelas, selanjutnya peneliti lain dapat menggunakan multiclass. Peningkatan akurasi pada SVM dapat dikombinasi dengan Partical Swarm Optimization (PSO).

\section{DAFTAR PUSTAKA}

[1] http://www.kpu.go.id/index.php/post/read/2015/3829/Arief-Tujuan-Pilkada-SerentakUntuk-Terciptanya-Efektivitas-dan-Efisiensi-Anggaran/berita, "Arief: Tujuan Pilkada Serentak Untuk Terciptanya Efektivitas dan Efisiensi Anggaran," 2015.

[2] Haewoon Kwak, Changhyun Lee, Hosung Park, and Sue Moon, "What is Twitter, a Social Network or a News Media?," 2010.

[3] Jianshu Weng, Ee-Peng Lim, Jing Jiang, and Qi He, "TwitterRank: Finding Topic-sensitive Influential Twitterers," 2010.

[4] Seyed-Ali Bahrainian and Andreas Dengel, "Sentiment Analysis using Sentiment Features," 2013.

[5] Umesh Rao Hodeghatta, "Sentiment Analysis of Hollywood Movies on Twitter," 2013.

[6] André L. F. Alves, Cláudio de S. Baptista, A. Anderson Firmino, Maxwell G. de Oliveira, and Anselmo C. de Paiva, "A Comparison of SVM Versus Naive-Bayes Techniques for," 2014.

[7] Andi Nurul Hidayat, "ANALISIS SENTIMEN TERHADAP WACANA POLITIK PADA," JURNAL ELEKTRONIK SISTIM INFORMASI DAN KOMPUTER (JESIK), vol. 1, p. 1, Januari-Juni 2015.

[8] Anuj Sharma and Shubhamoy Dey, "A Comparative Study of Feature Selection and Machine Learning Techniques for Sentiment Analysis," 2012.

[9] M. Fachrurrozi M.T. and Novi Yusliani M.T., "ANALISIS SENTIMEN PENGGUNA JEJARING SOSIAL MENGGUNAKAN METODE SUPPORT VECTOR MACHINE," 2015.

[10] Fatimah Ilona Asa Sabsono and Endang Ripmiatin, "Sentimen Analisis di Media Sosial Twitter Menggunakan Support Vectore Machine (SVM)," 2015.

[11] Abd. Samad Hasan Basari, Burairah Hussin, Gede Pramudya Ananta, and Junta Zeniarja, "Opinion Mining of Movie Review using Hybrid Method of Support Vector Machine and Particle Swarm Optimization," Desember 2013. 
[12] WEKA. Calcuration by SMO [Online]. http://weka.8497.n7.nabble.com/Calcuration-by-SMO-weights-td33491.html

[13] H. Witten and Eibe Frank, "Data Mining: Practical Machine Learning Tools and Techniques with Java Implementations," vol. 31, No. 1, March 2002. 